ISSN 0103-9954

\title{
COREIDAE (HETEROPTERA) ASSOCIADOS A ESPÉCIES FLORESTAIS
}

\section{COREIDAE (HETEROPTERA) ASSOCIATED WITH NATIVE FOREST PLANTS}

\author{
Adriane Brill Thum ${ }^{1}$ Ervandil Correia Costa ${ }^{2}$
}

\begin{abstract}
RESUMO
Com o objetivo de analisar qualitativamente e quantitativamente os Coreidae associados a diferentes essências florestais nativas, no período de agosto de 1993 a julho de 1995, foram coletados insetos em copas de dez espécies botânicas, localizadas em uma mata ciliar, no município de Caibaté-RS (Brasil). Realizou-se coletas quinzenais, utilizando-se um funil cônico confeccionado com folha de flandres $(2 \mathrm{~mm})$, tendo $70 \mathrm{~cm}$ de diâmetro na maior abertura e $63 \mathrm{~cm}$ de altura. Retirou-se uma amostra por espécie botânica e por data de coleta obtida através de dez sacudidas dos ramos sobre o funil. Realizadas as coletas, o material era levado ao Laboratório de Entomologia do Departamento de Defesa Fitossanitária - CCR, da Universidade Federal de Santa Maria-RS, onde realizou-se a triagem e identificação do material. Identificou-se um total de 11 espécies de Coreidae. Jadera sanguinolenta foi a espécie com maior número de indivíduos. Casearia sylvestris foi a planta hospedeira que abrigou maior número de espécies e maior número de insetos. Myrocarpus frondosus não hospedou nenhuma espécie de Coreidae.
\end{abstract}

Palavras-chave: Coreidae, entomofauna, essências florestais.

\begin{abstract}
Aiming at studying Correidae types and quantity associated to different native forest species, insects were sampled in canopies of ten botanical species at a forest border in Caibaté, RS, (Brazil) from August 1993 to July 1995. The insects were collected every fifteen days, by using a conical funnel made of tin can $(2 \mathrm{~mm})$ which has $70 \mathrm{~cm}$ diameter in the biggest opening and $63 \mathrm{~cm}$ of height. It was taken a sample from each botanical species and each date of collect after ten shakes of plant branches over the funnel. The insects were taken to Entomology Laboratory of Phytossanitary Defense Department, UFSM, where insect selection and identification were done. It was identified eleven (11) species of Coreidae. Jadera sanguinolenta was the species with the highest number of specimens. Casearia sylvestris was the botanical species which hosted the highest number of species and insects. Myrocarpus frondosus did not host any Coreidae species.
\end{abstract}

Key words: Coreidae, entomofauna, forest species.

1. Engenheira Florestal, Mestre em Engenharia Florestal. UFSM. 97.119-900. Santa Maria. RS.

2. Engenheiro Agrônomo, Dr., Prof. Titular do Departamento de Defesa Fitossanitária. UFSM. 97.119-900. Santa Maria. RS. 


\section{INTRODUÇÃO}

Conhecer a entomofauna dos ecossistemas florestais naturais é de fundamental importância para elucidar as relações existentes entre a flora e os insetos a ela associados, bem como para identificar espécies-praga que utilizam estes ambientes como abrigo e local de reprodução.

Algumas espécies de Coreidae foram citadas por SILVA et al. (1968), dentre elas Hypselonotus interruptus, Hyalymenus tarsatus, Jadera sanguinolenta, Megalotomus pallescens, Megalotomus rufipes, Phthia picta, Zicca nigropunctulata, tendo como plantas hospedeiras espécies de ciclo anual e/ou perenes, cultivadas ou não. GALLO et al. (1988) descreve Phthia picta atacando solanáceas.

Investigando insetos em algumas espécies florestais, COSTA et al. (1993) identificaram as seguintes espécies de Coreidae: Zicca próx. stalii, em pitangueira; Sethenira uruguayensis em eucalipto; Sethenira sp., Coribergia declivicollis, Hypselonotus interruptus e Scamurius próx. bachmanni em camboim.

Estudando coreídeos em espécies florestais exóticas, THUM \& COSTA (1995) e BRILL (1996) encontraram: Sethenira sp., Hypselonotus interruptus, Hyalymenus sp., Jadera sanguinolenta, Leptoglossus chilensis-concaviusculus coletados em Cupressus macrocarpa Hartw.; H. interruptus, Hyalymenus sp. e L. chilensis-concaviusculus em Acacia mearsii De Willd.; $L$. chilensis-concaviusculus em Casearia sylvestris.

Cinco espécies de Coreidae foram encontradas por BRILL (1996) em copas de essências florestais. COSTA et al. (1996) observaram seis espécies de Coreidae em três espécies de plantas hospedeiras da família das Myrtaceae.

A realização deste trabalho tem por objetivo, ampliar a determinações qualitativas e quantitativas da população de Coreidae e suas plantas hospedeiras.

\section{MATERIAL E MÉTODOS}

Realizou-se coletas quinzenalmente, no município de Caibaté, RS (Brasil), de agosto de 1993 a julho de 1995. As coletas foram realizadas em dez espécies botânicas: Rollinia rugulosa Schlechtendal (Annonaceae); Patagonula americana Linnaeus (Boraginaceae); Myrocarpus frondosus Freire Allemão (Leguminosae); Britoa guazumaefolia (Cambessedes) Legrand, Campomanesia xanthocarpa Berg., Eugenia uniflora Linnaeus e Myrciaria rivularis Cambessedes (Myrtaceae); Allophylus edulis (Saint-Hilaire) Roldkofer e Cupania vernalis Cambessedes (Sapindaceae).

$\mathrm{Na}$ execução da amostragem foi utilizado um funil cônico confeccionado com folha de flandres $(2 \mathrm{~mm})$, tendo $70 \mathrm{~cm}$ de diâmetro na maior abertura e $63 \mathrm{~cm}$ de altura. Adaptou-se um saco

Ciência Florestal, v.7, n.1, 1997 
plástico na extremidade de menor diâmetro para a retenção dos insetos coletados. Retirou-se de cada espécie vegetal somente uma amostra por data de coleta, sendo esta obtida através de dez sacudidas dos ramos sobre o funil. Foram realizadas 48 coletas durante o período.

Coletado o material, foi efetuada a triagem no Laboratório de Entomologia do Departamento de Defesa Fitossanitária da Universidade Federal de Santa Maria, Santa Maria - RS. Os espécimens da família Coreidae foram separados, identificados parte por comparação com os insetos pertencentes a coleção deste Departamento e os demais enviados a especialistas do grupo, para identificação.

\section{RESULTADOS E DISCUSSÃO}

Identificou-se 11 espécies de Coreidae, coletados no decorrer do levantamento. As espécies e suas referidas plantas hospedeiras encontram-se na Tabela 1.

TABELA 1: Número total de insetos de diferentes espécies de Coreidae por planta hospedeira, Caibaté-RS, 1993/1995.

\begin{tabular}{l|c|c|c|c|c|c|c|c|c|c|c|c}
\hline Espécie/Gênero & PT & CR & SC & GB & GP & GJ & CV & CB & AR & CC & Total & $\%$ \\
\hline Anasa lunicollis & - & - & - & - & - & - & 14 & - & - & - & 14 & 4,13 \\
Apidaurus sp. & 2 & - & - & - & - & - & - & - & - & - & 2 & 0,59 \\
Dalmatomammurius & - & - & - & 8 & - & - & - & - & - & - & 8 & 2,36 \\
vandoesburgi & & & & & & & & & & & & \\
Hyalymenus sp. & - & - & - & - & - & - & - & - & 15 & - & 15 & 4,43 \\
Hypselonotus interruptus & - & 16 & - & 7 & 14 & - & - & - & - & - & 37 & 10,91 \\
Jadera pectoralis & 3 & - & 7 & - & 26 & - & - & - & - & - & 36 & 10,62 \\
Jadera sanguinolenta & 14 & 29 & 19 & - & 13 & - & 11 & - & - & 45 & 131 & 38,64 \\
Megalotomus sp. & - & 16 & - & - & - & - & 16 & - & - & - & 32 & 9,44 \\
Phthia picta & - & 3 & - & 3 & - & 24 & - & - & - & - & 30 & 8,85 \\
Sethenira uruguaiensis & - & 12 & - & 2 & - & - & - & - & - & - & 14 & 4,13 \\
Zicca nigropuctulata & - & - & - & - & - & 20 & - & - & - & - & 20 & 5,90 \\
\hline Total & 19 & 76 & 26 & 20 & 53 & 44 & 41 & 0 & 15 & 45 & 339 & 100 \\
\hline \% & 6,51 & 22,42 & 7,67 & 5,90 & 15,63 & 12,98 & 12,09 & 0 & 4,43 & 13,27 & 100 & - \\
\hline
\end{tabular}

$\mathrm{PT}=$ Eugenia uniflora (Pitangueira); GB = Campomanesia xanthocarpa (Guabirobeira);

$\mathrm{CV}=$ Cupania vernalis (Camboatá-vermelho); $\mathrm{CR}=$ Casearia sylvestris (Carvalhinho);

$\mathrm{GP}=$ Myrciaria rivularis (Guapurití); $\mathrm{CB}=$ Myrocarpus frondosus (Cabriúva);

$\mathrm{SC}=$ Britoa guazumaefolia (Sete-capotes); GJ = Patagonula americana (Guajuvira);

$\mathrm{AR}=$ Rollinia rugulosa (Araticum); $\mathrm{CC}=$ Allophylus edulis (Chal-chal); - = Não ocorreu

Dos Coreidae coletados a espécie que apresentou maior número de indivíduos foi Jadera sanguinolenta, com $38,64 \%$ do total de espécimens coletados. Esta espécie também se fez presente em $60 \%$ das plantas hospedeiras estudadas. $J$. sanguinolenta já havia sido relatada por SILVA et al. (1968) em arroz e cafeeiro, por THUM \& COSTA (1995) e BRILL (1996) em Cupressus macrocarpa. 
Hypselonotus interruptus foi a segunda espécie de maior ocorrência, com 10,91\% do total coletado estando presente em três espécies plantas hospedeiras, seguida de Jadera pectoralis. A primeira espécie foi citada por SILVA et al. (1968) em culturas anuais, frutiferas e algumas espécies florestais, por COSTA et al. $(1993,1996)$ em camboim e por THUM \& COSTA (1995) em Acacia meanrsii, Caesalpinia peltophoroides e Cupressus macrocarpa, também é relatada por BRILL (1996) em duas espécies florestais. Ao passo que para a segunda espécie não existe nenhuma citação.

Das 11 espécies de Coreidae encontradas nesta pesquisa, oito se fizeram presentes nas plantas hospedeiras da família das Myrtaceae (Tabela 1), o que vem a corroborar com resultados observados por COSTA et al. (1996) que verificaram preferência semelhante no município de São Sepé - RS.

Rollinia rugulosa e Allophylus edulis foram hospedeiras, apenas de uma espécie de Coreidae, Hyalymenus sp. e Jadera sanguinolenta, respectivamente. A planta hospedeira que apresentou maior número de espécies e maior número de indivíduos foi Casearia sylvestris (carvalhinho). Já em Myrocarpus frondosus (cabriúva) não se coletou nenhuma espécie durante a realização da pesquisa, ficando evidenciado certa preferência por determinadas espécies de plantas hospedeiras, por parte dos Coreidae, que buscam local de abrigo, local de oviposição ou mesmo alimento. O fator determinante para que ocorra estas situações extremas, sem dúvida alguma é o arranjo ou distribuição dos ramos na formação das copas e a composição das folhas cuja denominação mais correta seria arquitetura da planta.

\section{CONCLUSÕES}

De acordo com os resultados obtidos e nas condições em que foi realizada a pesquisa, conclui-se que:

1- Onze espécies de Coreidae, são referidas para as diferentes plantas hospedeiras analisadas.

2 - Quantitativamente Jadera sanguinolenta é a espécie mais expressiva.

3 - Das plantas hospedeiras, Casearia sylvestris é a planta capaz de abrigar maior número de insetos. frondosus.

4 - Nenhuma espécie de Coreidae se fez presente nas coletas realizadas em Myrocarpus

5 - Os Coreidae demonstram preferência hospedeira. 


\section{BIBLIOGRAFIA}

BRILL, A.T. Hemípteros e homópteros recolectados en copas de diferentes espécies forestales. In: LATINOAMERICANO., 6 y CONGRESO NACIONAL DE ENTOMOLOGIA., 31, 1996, Cidade de Mérida. Memorias... Cidade de Mérida: Sociedade Mexicana de Entomologia, 1996. 214p. p.165.

COSTA, E.C., BOGORNI, P.C., MEDINA, L.D. Percevejos coletados em copas de diferentes espécies florestais: Coreidae - 1. In: JORNADA DE PESQUISA DA UFSM, 3., 1993, Santa Maria. Anais... Santa Maria: UFSM, 1993, 639p. p.371.

COSTA, E.C., BOGORNI,P.C., THUM,A.B. Percevejos coletados em copas de diferentes espécies florestais. Coreidae - 1. In: SIMPÓSIO SOBRE ECOSSISTEMAS FLORESTAIS DO MERCOSUL, 1., 1996, Santa Maria. Anais... Santa Maria, 1996.

GALLO, D., NAKANO, O., SILVEIRA NETO, S., CARVALHO, R.P.L.,BATISTA, G.C., BERTI FILHO, E., PARRA, J.R.P., ZUCCHI, R.A., ALVES, S.B. \& VENDRAMIN, J.D. Manual de Entomologia Agrícola. 2 ed., São Paulo, Ceres, 1988. 649p.

SILVA, A.G.A., GONÇALVES, A. J. L.; GOMES, J.; SILVA, M.N. \& SIMONI, L. de. Quarto catálogo dos insetos que vivem nas plantas do Brasil: seus parasitos e predadores. Rio de Janeiro, Ministério da Agricultura, 1968. Parte II, $2^{\circ}$ Tomo. 268p.

THUM, A.B., COSTA, E.C. Percevejos coletados em copas de diferentes espécies florestais exóticas. In: JORNADA INTEGRADA DE PESQUISA, EXTENSÃO E ENSINO, 2., 1995, Santa Maria. Anais... Santa Maria: UFSM, 1995. 1036p. p.596. 